\title{
OPEN Dryland irrigation increases accumulation rates of pedogenic carbonate and releases soil abiotic $\mathrm{CO}_{2}$
}

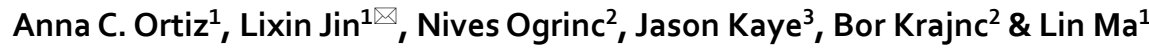

Agricultural fields in drylands are challenged globally by limited freshwater resources for irrigation and also by elevated soil salinity and sodicity. It is well known that pedogenic carbonate is less soluble than evaporate salts and commonly forms in natural drylands. However, few studies have evaluated how irrigation loads dissolved calcium and bicarbonate to agricultural fields, accelerating formation rates of secondary calcite and simultaneously releasing abiotic $\mathrm{CO}_{2}$ to the atmosphere. This study reports one of the first geochemical and isotopic studies of such "anthropogenic" pedogenic carbonates and $\mathrm{CO}_{2}$ from irrigated drylands of southwestern United States. A pecan orchard and an alfalfa field, where flood-irrigation using the Rio Grande river is a common practice, were compared to a nearby natural dryland site. Strontium and carbon isotope ratios show that bulk pedogenic carbonates in irrigated soils at the pecan orchard primarily formed due to flood-irrigation, and that approximately 20-50\% of soil $\mathrm{CO}_{2}$ in these irrigated soils is calcite-derived abiotic $\mathrm{CO}_{2}$ instead of soil-respired or atmospheric origins. Multiple variables that control the salt buildup in this region are identified and impact the crop production and soil sustainability regionally and globally. Irrigation intensity and water chemistry (irrigation water quantity and quality) dictate salt loading, and soil texture governs water infiltration and salt leaching. In the study area, agricultural soils have accumulated up to $10 \mathrm{wt} \%$ of calcite after just about 100 years of cultivation. These rates will likely increase in the future due to the combined effects of climate variability (reduced rainfall and more intense evaporation), use of more brackish groundwater for irrigation, and reduced porosity in soils. The enhanced accumulation rates of pedogenic carbonate are accompanied by release of large amounts of abiotic $\mathrm{CO}_{2}$ from irrigated drylands to atmosphere. Extensive field studies and modelling approaches are needed to further quantify these effluxes at local, regional and global scales.

Irrigated agriculture is expanding in drylands to produce crops that meet rising food demands and support local economy ${ }^{1,2}$. However, soil salinization due to continuous irrigation is a global problem that affects agricultural soils from Asia, Europe, North America, and Australia, covering approximately $20 \%$ of irrigated area around the world ${ }^{3-5}$. Soils have been converted to managed agricultural fields along the Rio Grande valley in western Texas and southern New Mexico for more than 100 years $^{6}$. This region is a typical dryland system with mean annual precipitation at $\sim 16-25 \mathrm{~cm}$ and annual potential evapotranspiration at $\sim 194 \mathrm{~cm}^{7,8}$. During growing seasons, large areas of cropland are inundated by diverting Rio Grande river water through canals and by pumping groundwater from deep aquifers. Such flood irrigation is not a water-conservative method and has led to high evaporative water loss especially during hot and dry summers, salt accumulation, and a decrease in soil permeability, quality and productivity ${ }^{8-14}$.

Soil $\mathrm{CO}_{2}$ is produced naturally by decomposition of organic matter, root respiration and microbial respiration; in dryland environments, an additional abiotic source is pedogenic carbonate precipitation (Fig. 1). Indeed, irrigation practices deliver large amounts of dissolved $\mathrm{Ca}^{2+}$ and $\mathrm{HCO}_{3}^{-}$to soils, leading to precipitation of pedogenic carbonate even before water-soluble evaporite salts such as gypsum and halite ${ }^{12,14-16}$. To date, however, a limited number of studies have identified the accelerated accumulation rates of pedogenic carbonate (secondary

${ }^{1}$ Department of Geological Sciences, University of Texas at El Paso, 500 W. University Ave, El Paso, TX 79968, USA. ${ }^{2}$ Department of Environmental Sciences, Jožef Stefan Institute, Ljubljana, Slovenia. ${ }^{3}$ Department of Ecosystem Science and Management, Pennsylvania State University, University Park, PA 16802, USA. ${ }^{\boxplus}$ email: ljin2@utep.edu 


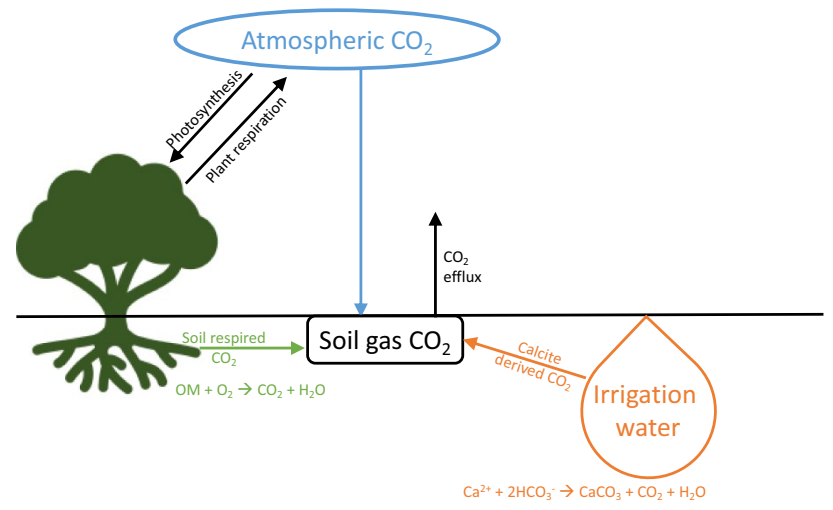

Figure 1. A simplified conceptual model to highlight major $\mathrm{CO}_{2}$ fluxes and calcite formation pathways in the agricultural fields. Soil $\mathrm{CO}_{2}$ is contributed by atmospheric, soil respired and calcite derived $\mathrm{CO}_{2}$.

calcite) in such agricultural settings ${ }^{17-24}$, and only a few have attempted to measure the release of $\mathrm{CO}_{2}$ (referred to as abiotic $\mathrm{CO}_{2}$ ) through carbonate precipitation ${ }^{25-30}$ :

$$
\mathrm{Ca}_{(\mathrm{aq})}^{2+}+2 \mathrm{HCO}_{3(\mathrm{aq})}^{-} \leftrightarrow \mathrm{CaCO}_{3(\mathrm{~s})}+\mathrm{CO}_{2(\mathrm{~g})}+\mathrm{H}_{2} \mathrm{O}_{(\mathrm{aq})}
$$

It is essential to identify and quantify such abiotic $\mathrm{CO}_{2}$, investigate the controls on its efflux from soils to atmosphere, and upscale the interactive effects of climate change and irrigation expansion on $\mathrm{C}$ cycling in drylands.

Here we report a case study to reveal the linkages among irrigation, salt loading and $\mathrm{CO}_{2}$ dynamics from dryland areas, in the Rio Grande valley near El Paso, Texas. Here, soils are developed on ancestral Rio Grande floodplain sediments and natural pedogenic carbonate has formed naturally for thousands of years ${ }^{31,32}$. The study sites include two agricultural sites and one natural site (Fig. S1), and both farms have been intensively cultivated and flood irrigated for the last 100 years $^{6}$. We hypothesize that flood irrigation has produced younger pedogenic carbonate of different carbon and strontium isotopic signatures as compared to the natural counterparts, and detectable abiotic $\mathrm{CO}_{2}$. This study builds on previous investigation on sources and controls of soil salinity in agricultural soils ${ }^{12-14}$, and collects new $\mathrm{C}$ and $\mathrm{Sr}$ isotope data to determine the relative contribution of irrigationinduced reaction (1) to the overall soil $\mathrm{CO}_{2}$ and bulk soil pedogenic carbonate.

\section{Methods and materials}

Study sites. Our study focused on one natural site and two agricultural sites along the Rio Grande valley in southern New Mexico and western Texas, USA (Fig. S1A). Soils in all sites are developed on alluvial sediments of the ancient Rio Grande river ${ }^{14}$. The two agricultural sites are located in the El Paso County of western Texas: a pecan orchard in Tornillo, TX and an alfalfa field in El Paso, TX. The pecan field has been cultivated for pecans for approximately last 40 years, and for cotton for 60 years prior (Fig. S1B, S1C). The alfalfa field has only been cultivated for alfalfa. With low annual mean precipitation in the American southwest, these agricultural fields are flood irrigated, primarily with Rio Grande river water. The pecan orchard is typically irrigated from April to October during the growing season, once every two to three weeks with approximately 10 to 12 irrigation events or on average $1.5 \mathrm{~m}$ of water annually. When river water is insufficient, the pecan orchard would be irrigated using local groundwaters, while the alfalfa field is left fallow. In addition, the pecan orchard is fertilized and also amended by sulfur and gypsum pellets to lower soil sodicity ${ }^{14}$. The alfalfa site is less managed and has no history of soil amendments or fertilization. A natural site was selected for comparison, in the Chihuahuan desert scrub rangeland outside of Fabens, Texas, that has never been cultivated or irrigated (Fig. S1D).

Soil and dust sample collection and characterization. These three sites have been previously studied for soil texture, salinity and sodicity ${ }^{12-14,33}$. Soil salinity is measured as electrical conductivity (EC) and sodicity as sodium adsorption ratio (SAR), the ratio of sodium concentration over the square root of the sum of calcium and magnesium concentrations in a soil slurry. Soil sodicity controls clay behavior, soil structure and soil permeability. Archived soil, dust and water samples were used for this study and their collection is briefly described here. At the pecan orchard, two soil cores were collected at $\sim 10 \mathrm{~cm}$ increment resolution, with contrasting texture: Pecan_Fine and Pecan_Coarse, to the depths of $250 \mathrm{~cm}$ and $300 \mathrm{~cm}$ respectively. Pecan_Fine soils have a layer of clayey soils around $100-150 \mathrm{~cm}$ and have much higher soil salinity and sodicity than the sandy Pecan_Coarse soils. These two soil profiles are less than $20 \mathrm{~m}$ apart and undergo the same soil amendments and irrigation schedule. However, the Pecan_Fine and Pecan_Coarse soils are characterized by visually distinct pecan growth, mainly due to different amounts of salt buildup. A $60-\mathrm{cm}$ deep soil core was previously collected and characterized in an alfalfa field (as alfalfa) ${ }^{12}$ and as Alfalfa_Fine_D ${ }^{14}$ in El Paso, Texas. These soils are silty clay loam alluvium of Harkey-age (NRCS Custom Soil Report). As a natural site for comparison, a 110$\mathrm{cm}$ deep core was augured at Fabens, Texas and studied for soil salinity and dust deposition ${ }^{14}$. 
Dust, as a potential source of $\mathrm{Ca}$ in pedogenic carbonates, was sampled at both the pecan orchard site and the natural Fabens site using passive dust traps $150 \mathrm{~cm}$ above ground ${ }^{34-36}$. Both dust traps were maintained for one year (2015-2016) and a single sample was collected from each representing a composite of dry and wet deposition and by washing the beads.

Soil carbon (SC) and organic carbon (SOC) contents were quantified using a LECO SC632 analyzer at the Low-Temperature Geochemistry Laboratory of the University of Texas at El Paso (UTEP). About $0.2 \mathrm{~g}$ of ground bulk soil samples was weighed, mixed with combustion catalyst, and combusted in the LECO furnace at $1450{ }^{\circ} \mathrm{C}$. The moisture was then removed from the resultant gases and $\mathrm{CO}_{2}$ was quantified to calculate SC. Two standards of different carbon contents and different weights were used for calibration. A soil reference material is run with the samples as checks and the measured values are within $0.1 \mathrm{wt} \%$ of reference values. Another aliquot of bulk soils was treated by $1: 1 \mathrm{HCl}$ to remove carbonate (also known as soil inorganic carbon; SIC) and then dried in the oven at $60^{\circ} \mathrm{C}$. The carbon content measured on these acid-leached soils was considered as SOC, and SIC was calculated as the difference between SC and SOC. Weight percent of calcite was then computed from SIC based on calcite stoichiometry $\left(\mathrm{CaCO}_{3}\right)$. Two pure calcite samples were run with the same procedure and measured $\mathrm{C}$ contents were lower than $0.02 \%$ ensuring complete release of $\mathrm{C}$ during acidification.

The $\mathrm{C}$ isotopes of organic matter $\left(\delta^{13} \mathrm{C}_{\mathrm{SOC}}\right)$ and carbonate $\left(\delta^{13} \mathrm{C}_{\mathrm{CaCO} 3}\right)$ in the selected soil samples were analyzed on a continuous-flow isotope ratio mass spectrometer (IRMS; Finnigan Delta PlusXL) at the University of Arizona. Precision for $\delta^{13} \mathrm{C}_{\mathrm{SOC}}$ was $\pm 0.1 \%$ or better $(1 \sigma)$. In order to measure $\mathrm{C}$ isotope composition of the carbonate minerals $\left(\delta^{13} \mathrm{C}_{\mathrm{CaCO} 3}\right)$, soil samples were reacted with dehydrated $\mathrm{H}_{3} \mathrm{PO}_{4}$ under vacuum at $70{ }^{\circ} \mathrm{C}$. The released $\mathrm{CO}_{2}$ was then measured by an IRMS (Finnigan MAT 252). For these carbon isotope measurements, precision is better than $\pm 0.08 \%$ o $(1 \sigma)$.

The sequential extraction of water leachable and acid leachable fractions of the soils were conducted for the pecan, alfalfa, and natural Fabens sites as well as two dusts from Fabens and pecan field ${ }^{14}$. The water fraction was used to dissolve evaporite salts, such as $\mathrm{CaCl}_{2}, \mathrm{NaCl}, \mathrm{CaSO}_{4}$ and $\mathrm{Na}_{2} \mathrm{SO}_{4}$, and directly linked to irrigation through soil salinity. Specifically, $10 \mathrm{~g}$ of a soil sample and $1 \mathrm{~g}$ of dust sample was weighed into a centrifuge tube, with $30 \mathrm{~mL}$ of de-ionized water $(18.2 \mathrm{M} \Omega)$. The slurry was shaken for $15 \mathrm{~min}$ on a shaker and centrifuged at $3500 \mathrm{rpm}$ for ten minutes. The supernatant was passed through with a $0.45 \mu \mathrm{m}$ filter and weighed. Exchangeable cations were extracted with $25 \mathrm{~mL}$ of $0.1 \mathrm{M} \mathrm{BaCl}_{2}-0.1 \mathrm{M} \mathrm{NH}_{4} \mathrm{Cl}$ from soils and dusts between water soluble and acid leachable fractions, to remove cations adsorbed to clays and $\mathrm{Fe}$ or $\mathrm{Al}$ oxyhydroxides. The acid leachable fraction dissolved carbonate minerals such as secondary calcite and amorphous $\mathrm{Fe}$ or $\mathrm{Al}$ oxides if present. Specifically, $20 \mathrm{~mL}$ of $1 \mathrm{M}$ or $2 \mathrm{M}$ acetic acid was added onto soil residue from the CEC fraction, depending on the soil inorganic carbon concentrations. The mixture was shaken for $6 \mathrm{~h}$ and centrifuged at $2500 \mathrm{rpm}$ for $20 \mathrm{~min}$ and the supernatant filtered with $0.45 \mu \mathrm{m}$ paper filter. The soil residue was washed again with $3 \mathrm{~mL}$ of $1 \mathrm{M}$ or $2 \mathrm{M}$ acetic acid to ensure the carbonate fraction was completely dissolved and collected. Two aliquots of acetic acid leachates were combined, dried and dissolved in $2 \% \mathrm{HNO}_{3}$. Leachates from these two sequential extractions were analyzed for major elements to evaluate soil salinity and sodicity (water leachable fraction) and for abundance of pedogenic carbonate (based on $\mathrm{Ca}$ in acid leachable fraction) ${ }^{14}$. These leachates are analyzed for $\mathrm{Sr}$ isotopes as discussed below.

Water sample collection and characterization. Nested lysimeters were placed at 15, 30, 60, and $120 \mathrm{~cm}$ depths for both pecan sites, Pecan_Fine and Pecan_Coarse. Rio Grande and groundwater irrigation samples, as well as soil waters, were only collected from the pecan orchard. Lysimeter waters were collected and filtered using $0.45 \mu \mathrm{m}$ membrane filters. The $\mathrm{pH}, \mathrm{EC}$, alkalinity (equivalent of dissolved inorganic carbon, DIC at this $\mathrm{pH}$ ), concentrations of major ions, and saturation indexes with respect to calcite were previously reported ${ }^{14}$. Irrigation water samples collected at the study sites included Rio Grande surface waters (IRW_RG), and local groundwaters (IRW_GW), where the groundwater is much more concentrated than river water, with higher $\mathrm{Na}^{+}$and $\mathrm{Ca}^{2+}$ concentrations and thus higher potential to increase soil salinity and sodicity ${ }^{14}$. For these water samples, new $\mathrm{C}$ and $\mathrm{Sr}$ isotope data were collected and reported (Appendix Table 2). The $\mathrm{C}$ isotopes of dissolved inorganic carbon (with $\mathrm{HCO}_{3}{ }^{-}$as the dominant $\mathrm{DIC}$ species, average $\mathrm{pH}=7.74 ; \delta^{13} \mathrm{C}_{\mathrm{DIC}}$ ) was measured on a continuous-flow gas-ratio mass spectrometer (ThermoQuest Finnigan Delta PlusXL) coupled with a Gasbench automated sampler at the Environmental Stable Isotope Laboratory at the University of Arizona. The samples were acidified with phosphoric acid at room temperature in Exetainer vials previously flushed with He gas. The precision in $\delta^{13} \mathrm{C}_{\mathrm{DIC}}$ is better than $\pm 0.3 \%$ o $(1 \sigma)$.

Soil leachates and water samples were analyzed for Sr isotope analysis. Twenty-five milliliters of the fullstrength filtered waters were dried in $30 \mathrm{~mL}$ Teflon beakers, then dissolved in $0.5 \mathrm{~mL}$ of $3.5 \mathrm{~N} \mathrm{HNO}_{3}{ }^{-}$before the Sr elution sequence for isotopic analysis. Strontium purification was conducted in a Class 100/1000 clean room-laminar air fume hood with Eichron ${ }^{\circledR}$ Sr 100-150 $\mu \mathrm{m}$ resin in $1.5 \mathrm{~mL}$ Teflon columns at UTEP. Two elution $\mathrm{Sr}$ purification sequences were conducted to attain an evaporable aliquot for analysis. Seven rinses with $3.5 \mathrm{~N} \mathrm{HNO}_{3}$ acid were performed in each sequence then an eighth rinse with $0.05 \mathrm{~N} \mathrm{HNO}_{3}$ to yield the purified sample. All purified samples were then analyzed for ${ }^{87} \mathrm{Sr} /{ }^{86} \mathrm{Sr}$ isotopes on the multi-collector inductively coupled plasma mass spectrometry (MC-ICP-MS) at UTEP using standard-sample bracketing method ${ }^{37}$. The Sr isotope bracketing standard SRM 987 yielded average ${ }^{87} \mathrm{Sr} /{ }^{86} \mathrm{Sr}$ ratios of $0.710235 \pm 0.000005(2 \mathrm{SE}, \mathrm{n}=32)$. For quality control purposes, USGS BCR2 rock standards were treated as bulk samples, with measured average ${ }^{87} \mathrm{Sr} /{ }^{86} \mathrm{Sr}$ ratios of $0.70502 \pm 0.00001(2 \mathrm{SE}, \mathrm{n}=9)$ that were within the values reported in literature $(0.70502)^{38}$. Sr blanks were negligible pico-gram scales ( $\sim 80 \mathrm{pg})$. For soil leachates, the uncertainty is typically within 0.0001 (2SE) due to low amounts of Sr used for analysis except for several soils on the water soluble fraction. For water samples, ${ }^{87} \mathrm{Sr} /{ }^{86} \mathrm{Sr}$ has a much lower uncertainty at $0.00002(2 \mathrm{SE}, \mathrm{n}=7)$ as a result of high amounts of Sr used for analysis. 


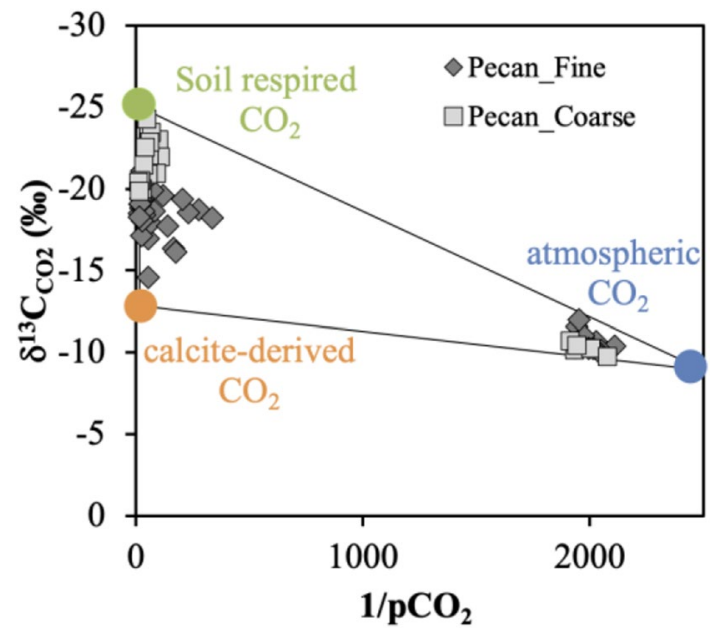

Figure 2. Keeling plot shows soil $\mathrm{CO}_{2}$ is contributed by three endmember mixing (atmospheric, soil respired and calcite-derived abiotic) in two soil profiles. Pecan_Fine has finer soil texture and higher calcite content than Pecan_Coarse, and soil $\mathrm{CO}_{2}$ in Pecan_Fine receives more calcite-derived abiotic $\mathrm{CO}_{2}$ contribution. Pecan Coarse soils support larger trees and so, produce more soil respired $\mathrm{CO}_{2}$. The atmospheric $\delta^{13} \mathrm{C}_{\mathrm{CO} 2}$ is $-8.9 \%{ }^{43}$.

Soil gas sample collection and analyses. Two nests of soil gas tubes were installed at the Pecan Fine and Pecan_Coarse sites at four depths $(15,30,60$ and $120 \mathrm{~cm})$ and sampled following a modified USGS protocol $^{39,40}$. Soil gas samples were collected using $60-\mathrm{mL}$ gas-tight plastic syringes and needles after purging two tube volumes to clear the sampler tube. Gas samples were immediately transferred to pre-evacuated $15-\mathrm{mL}$ LETCO ${ }^{\circ}$ glass vials. Additional atmospheric gas samples for $\mathrm{pCO}_{2}$ and $\delta^{13} \mathrm{C}_{\mathrm{CO} 2}$ were taken as local atmospheric endmembers, as well as for quality control. Gas samples were collected prior to irrigation and also one week after each flooding event, when the pecan field was dry enough to be accessible for soil gas sampling.

Soil gas $\mathrm{CO}_{2}$ concentrations $\left(\mathrm{pCO}_{2}\right)$ were measured by a LiCOR 7000 gas analyzer, calibrated with $\mathrm{CO}_{2}$ standards with concentrations of 970 and 10,300 ppmv at Pennsylvania State University. Check standards were analyzed along with unknown samples and the precision in $\mathrm{CO}_{2}$ concentrations is better than $\pm 5 \%$ of the reference values. The isotopic composition of soil $\mathrm{CO}_{2}$ was determined using a Europa 20-20 continuous flow Isotope Ratio Mass Spectrometer (IRMS) with an ANCA-TG preparation module for trace gas samples at the Jozef Stefan Institute in Slovenia. Gas samples were flushed with He across two chemical traps that removed water and then trapped the $\mathrm{CO}_{2}$. Precision in $\delta^{13} \mathrm{C}_{\mathrm{CO} 2}$ is better than $\pm 0.1 \%$ o $(1 \sigma)$, based on repeated internal standards.

\section{Results and discussion}

Controls on $\mathrm{C}$ isotope compositions of soil gas $\mathrm{CO}_{2}$ of an intensively irrigated Pecan field. The $\mathrm{pCO}_{2}$ of soil gases within the pecan orchard increases with depth (Appendix Table 1; Fig. S2A), characterized by a typical diffusion profile where $\mathrm{CO}_{2}$ is emitted to atmosphere ${ }^{39,41}$. Up to 74,000 ppm, or almost 200 times of the atmospheric $\mathrm{CO}_{2}$ level are observed in deep soils, below $60 \mathrm{~cm}$ depth. These concentrations are even higher than some natural vegetated systems ${ }^{39,40,42}$, suggesting enhanced soil respiration, root respiration and microbial activities as expected from soil cultivation and growth of pecan trees. The soil organic carbon (SOC) contents in both soil profiles are high near ground surface, at $~ 1.5 \mathrm{wt} \%$, and decreases sharply with depth (Fig. S3A).

The isotope ratio of soil $\mathrm{CO}_{2}\left(\delta^{13} \mathrm{C}_{\mathrm{CO} 2}\right)$ varied dramatically with depth and between Pecan_Fine and Pecan_ Coarse sites (Fig. S2B). The Keeling plot revealed two clusters in all soil gas samples, with at least three endmembers of different $\mathrm{C}$ isotope compositions (Fig. 2). Soil gases from shallow depths are closer to the atmospheric endmember ${ }^{43}$ (blue circle). Soil respired $\mathrm{CO}_{2}$ endmember (green circle in Fig. 2) has the same carbon isotope compositions as soil organic carbon $\left(\delta^{13} \mathrm{C}_{\mathrm{SOC}}\right)$ between -21.5 and $-24.5 \%$ (Fig. S3B). The third possible $\mathrm{CO}_{2}$ endmember (calcite-derived, abiotic) is discussed below (Orange circle in Fig. 2).

The $\delta^{13} \mathrm{C}_{\mathrm{DIC}}$ of the Rio Grande water samples used for irrigation ranges from -10.4 to $-6.3 \%$, on average $-7.3 \%$ o $(n=6)$; while groundwaters used for irrigation have more negative $\delta^{13} \mathrm{C}_{\mathrm{DIC}}$ ratios, averaging at $-11.3 \%$ $(\mathrm{n}=2)$ (Appendix Table 2). The $\delta^{13} \mathrm{C}$ of DIC, $\mathrm{CaCO}_{3}$ and $\mathrm{CO}_{2}$ constituents can be modeled using a Rayleigh fractionation when irrigation water or soil water evaporates, and $\mathrm{CaCO}_{3}$ and $\mathrm{CO}_{2}$ form according to Reaction (1). This process assumes an open system where DIC in soil water is an isotopically homogenous and finite reservoir, and the reaction products $\left(\mathrm{CaCO}_{3}\right.$ and $\left.\mathrm{CO}_{2}\right)$ that are instantaneously formed are always at isotopic equilibrium with remaining reactant (DIC) and are then continuously removed and isolated from the liquid phase (DIC) ${ }^{44}$. The fractionation factors between calcite and DIC (namely $\mathrm{HCO}_{3}{ }^{-}$at neutral $\mathrm{pH}$, as observed in the irrigation water) and between $\mathrm{CO}_{2}$ and DIC are assumed to be constant, and at $20^{\circ} \mathrm{C}$, the average soil temperature at the field sites, $\varepsilon^{13} \mathrm{C}_{\mathrm{CO} 2(\mathrm{~g}) \text { - } \mathrm{HCO} 3}$ is $-8.5 \%$ and $\varepsilon^{13} \mathrm{C}_{\mathrm{CaCO} 3(\mathrm{~s})-\mathrm{HCO} 3}$ is $2.6 \%{ }^{44}$. We used an initial DIC of $4 \mathrm{mM}$, and modelled the evolution of carbon isotopes with each step of $0.1 \mathrm{mM}$ DIC (Fig. 3). The continuous production of calcite and $\mathrm{CO}_{2}$ leads to higher $\delta^{13} \mathrm{C}_{\mathrm{DIC}}$ in the residual soil water as reaction proceeds (Fig. 3). As a result, the solid and gas phases from each precipitation step (dashed lines) become more enriched in $\delta^{13} \mathrm{C}$. 


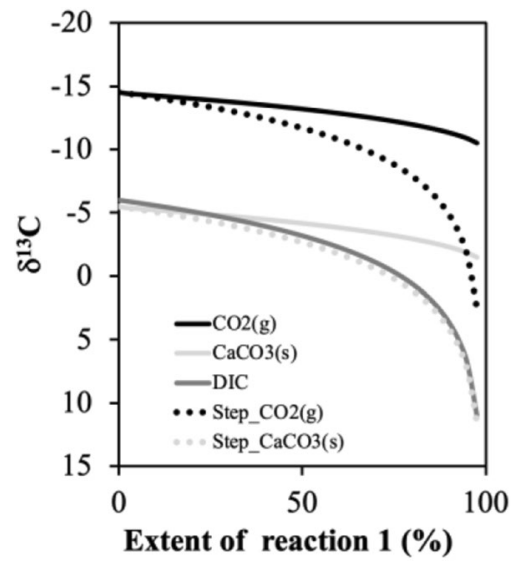

Figure 3. Evolution in $\delta^{13} \mathrm{C}$ values of $\mathrm{CaCO}_{3}$ and $\mathrm{CO}_{2}$ is modelled assuming Rayleigh fractionation, as DIC and $\mathrm{Ca}^{2+}$ in the irrigation water slowly precipitate out according to chemical reaction (1) with initial $\delta^{13} \mathrm{C}_{\text {DIC }}$ at $-6 \%$. Isotopic composition is plotted as dotted lines for each step or as solid lines cumulatively, for each species (black for $\mathrm{CO}_{2}(\mathrm{~g})$, grey for $\mathrm{CaCO}_{3}(\mathrm{~s})$ and dark grey for DIC). When all DIC is converted to calcite and $\mathrm{CO}_{2}$, extent of the reaction moves from 0 to $100 \%$, and the carbon isotopes of these endmembers are derived $\left(\delta^{13} \mathrm{C}_{\mathrm{CaCO} 3}=-1.75 \% ; \delta^{13} \mathrm{C}_{\mathrm{CO} 2}=-12.85 \%\right.$ ) .

$$
\begin{gathered}
\delta^{13} \mathrm{C}_{\mathrm{CO} 2(\mathrm{t}+1)}=\delta^{13} \mathrm{C}_{\mathrm{DIC}(\mathrm{t})}-8.5 \% ; \quad \delta^{13} \mathrm{C}_{\mathrm{CaCO} 3(\mathrm{t}+1)}=\delta^{13} \mathrm{C}_{\mathrm{DIC}(\mathrm{t})}+2.6 \% \\
\delta^{13} \mathrm{C}_{\mathrm{DIC}(\mathrm{t}+1)} * \mathrm{DIC}_{(\mathrm{t}+1)}=\delta^{13} \mathrm{C}_{\mathrm{DIC}(\mathrm{t})} * \mathrm{DIC}_{(\mathrm{t})}+\delta^{13} \mathrm{C}_{\mathrm{CO} 2(\mathrm{t}+1)} *\left[\mathrm{CO}_{2}\right]+\delta^{13} \mathrm{C}_{\mathrm{CaCO} 3(\mathrm{t}+1)} *\left[\mathrm{CaCO}_{3}\right]
\end{gathered}
$$

According to Reaction (1), the amount of $\mathrm{CO}_{2}$ or $\mathrm{CaCO}_{3}$ formed during each step:

$$
\left[\mathrm{CO}_{2}\right]=\left[\mathrm{CaCO}_{3}\right]=1 / 2\left(\mathrm{DIC}_{(\mathrm{t}+1)}-\mathrm{DIC}_{(\mathrm{t})}\right)
$$

The $\mathrm{Ca}^{2+} / \mathrm{DIC}$ molar ratios are variable in the Rio Grande river water, and much greater than 2 in the local groundwater (Appendix Table 2) ${ }^{14}$; overall there should be a $\mathrm{Ca}^{2+}$-surplus after all DIC precipitates out of soil water according to Reaction (1). This is consistent with the presence of water-soluble and Ca-bearing evaporite salts in these soils ${ }^{12,14}$.

When $100 \%$ of DIC reacts from the consequent drying of this irrigation event, mass balance considerations require that the isotope content of the total accumulated gas $\mathrm{CO}_{2}$ and solid $\mathrm{CaCO}_{3}$ approaches the initial water DIC:

$$
\begin{gathered}
\delta^{13} \mathrm{C}_{\mathrm{DIC}} * \mathrm{DIC}=\delta^{13} \mathrm{C}_{\mathrm{CO} 2} *\left[\mathrm{CO}_{2}\right]+\delta^{13} \mathrm{C}_{\mathrm{CaCO} 3} *\left[\mathrm{CaCO}_{3}\right] \\
\text { While }\left[\mathrm{CO}_{2}\right]=\left[\mathrm{CaCO}_{3}\right]=1 / 2 \mathrm{DIC}
\end{gathered}
$$

Rearranging Eq. (2) the difference in $\mathrm{C}$ isotopes between $\mathrm{CaCO}_{3}$ and $\mathrm{CO}_{2}$ is always:

$$
\delta^{13} \mathrm{C}_{\mathrm{CaCO} 3}-\delta^{13} \mathrm{C}_{\mathrm{CO} 2}=11.1 \%
$$

Thus Eq. (5) becomes: $\delta^{13} \mathrm{C}_{\mathrm{DIC}}{ }^{\star} \mathrm{DIC}=1 / 2 \mathrm{DIC} *\left(2 \delta^{13} \mathrm{C}_{\mathrm{CaCO} 3}-11.1 \% 0\right)$ and with $\delta^{13} \mathrm{C}_{\mathrm{DIC}}=-7.3 \% 0, \delta^{13} \mathrm{C}_{\mathrm{CaCO} 3}$ $=(-14.6+11.1) / 2=-1.75 \% ; \delta^{13} \mathrm{C}_{\mathrm{CO} 2}=-12.85 \%$.

This is consistent with the model results in Fig. 3: the $\delta^{13} \mathrm{C}_{\mathrm{CaCO} 3}$ of all calcite that precipitates out is estimated at $-1.75 \%$ and the $\delta^{13} \mathrm{C}_{\mathrm{CO} 2}$ of all $\mathrm{CO}_{2}$ is at $-12.85 \%$. This inclusion of the calcite-derived abiotic $\mathrm{CO}_{2}$ endmember explains the deviation of soil gas $\mathrm{CO}_{2}$ cluster from the atmosphere-soil respiration mixing curve. Our study has observed a detectable soil $\mathrm{CO}_{2}$ from the calcite precipitation, loaded and driven by irrigation.

For deep soil gases $\left(60 \mathrm{~cm}\right.$ or deeper) without the influence of atmospheric $\mathrm{CO}_{2}$, a two-component mixing system ( $\mathrm{A}$ = irrigation-derived abiotic $\mathrm{CO}_{2}, \mathrm{~B}=$ soil respired $\mathrm{CO}_{2}$ ) can be used to calculate the fraction of $\mathrm{CO}_{2}$ in the bulk soil gas (mix) from source $\mathrm{A}$ :

$$
X_{A}=\frac{R_{m i x}-R_{B}}{R_{A}-R_{B}}
$$

where $\mathrm{R}_{\mathrm{A}}=\delta^{13} \mathrm{C}_{\mathrm{CO} 2}=-12.85 \%$; $\mathrm{R}_{\mathrm{B}}=\delta^{13} \mathrm{C}_{\mathrm{CO} 2}=-24.5 \%$; and $\mathrm{R}_{\text {mix }}=\delta^{13} \mathrm{C}_{\mathrm{CO} 2}=-18.8 \pm 1.5 \%$ o $\mathrm{n}=36$, at Pecan_Fine $)$ or $-21.7 \pm 1.4 \%$ o $(\mathrm{n}=14$, at Pecan_Coarse $)$. Solving for $\mathrm{X}_{\mathrm{A}}$, the irrigation-derived abiotic $\mathrm{CO}_{2}$ at the clayey Pecan_ Fine site is shown to contribute $\sim 49 \%$ (range: $37 \%$ to $62 \%$ ) of bulk $\mathrm{CO}_{2}$ at deeper soils where atmospheric input is negligible, much higher than at the sandy Pecan_Coarse site (average 24\%, range: 12 to 36\%). This difference is attributed to contrasting soil texture and water dynamics. First, clayey soils at the Pecan_Fine site reduced 

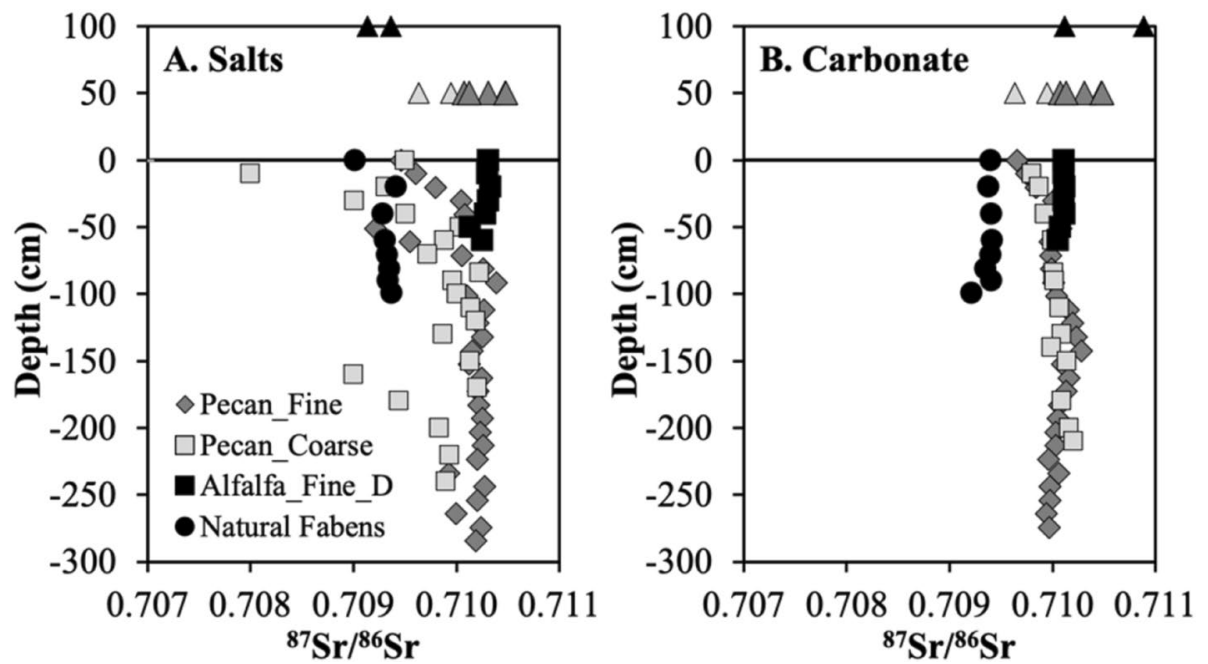

Figure 4. Depth profiles of ${ }^{87} \mathrm{Sr} /{ }^{86} \mathrm{Sr}$ ratios in evaporite salts (A, water leachable fraction) and pedogenic carbonate (B, acid leachable fraction) at three agricultural sites (Pecan_Fine and Pecan_Coarse at a pecan orchard, Alfalfa_Fine_D at an alfalfa field) and the natural Fabens site nearby. Also shown are Sr isotope compositions of two dust samples (black triangles, plotted at depths of $100 \mathrm{~cm}$ ) and irrigation waters (plotted at $50 \mathrm{~cm}$; light triangles for groundwater, IRW_GW and darker triangles for the Rio Grande, IRW_RG).
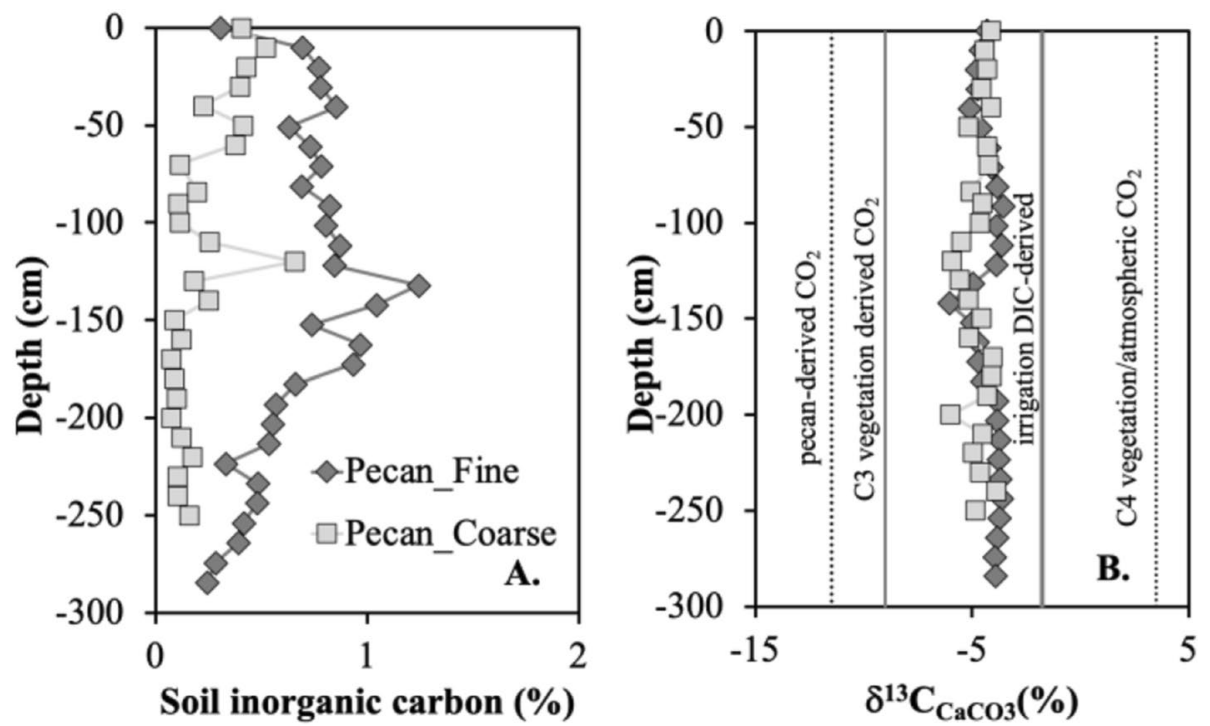

Figure 5. Depth profiles of soil inorganic carbon concentrations $(\mathbf{A})$ and carbon isotopes $\left(\delta^{13} \mathrm{C}_{\mathrm{CaCO}}\right)(\mathbf{B})$ at the Pecan_Fine and Pecan_Coarse sites. Vertical dotted in $(\mathbf{B})$ are $\delta^{13} \mathrm{C}_{\mathrm{CaCO} 3}$ values of natural pedogenic carbonates at equilibrium with natural $\mathrm{C} 3$ or $\mathrm{C} 4$ types of vegetation. The $\delta^{13} \mathrm{C}_{\mathrm{CaCO} 3}$ at equilibrium with atmospheric $\mathrm{CO}_{2}$ overlaps with that of typical C4 vegetation. The solid lines are $\delta^{13} \mathrm{C}_{\mathrm{CaCO} 3}$ of anthropogenic pedogenic carbonates at equilibrium with DIC in irrigation water and with organic matter of the pecan trees.

water infiltration and leaching, and promoted higher salt buildup; here, the soil salinity exceeded tolerance levels of pecan trees and stunted their growth. Thus less soil respired $\mathrm{CO}_{2}$ was produced at the Pecan_Fine soils than Pecan_Coarse soils. Second, salt buildup was more pronounced at the Pecan_Fine site, including secondary calcite (Fig. 5A, see below). Therefore, more abiotic $\mathrm{CO}_{2}$ is expected to be released from calcite precipitation at the Pecan_Fine site.

Independently, the relative importance of these two sources can be evaluated by a mass balance calculation. Alkalinity (a proxy of DIC at the measured $\mathrm{pH} 7.2-8.1)$ of the irrigation water is at $3.6 \pm 0.1 \mathrm{meq} / \mathrm{L}(\mathrm{n}=5)$ for the Rio Grande and $6.1 \pm 1.0 \mathrm{meq} / \mathrm{L}(\mathrm{n}=2)$ for the groundwater (Appendix Table 2). On average, 5 inches of water $(12.7 \mathrm{~cm})$ are used for an irrigation event, equivalent of $127 \mathrm{~L} / \mathrm{m}^{2}$. Thus, the calcite or abiotic $\mathrm{CO}_{2}$ produced through Reaction (1) will be half of the DIC loaded by the irrigation water (e.g., Rio Grande) or 0.23 mol over 
$1 \mathrm{~m}$ by $1 \mathrm{~m}$ ground surface $\left(\mathrm{S}=1 \mathrm{~m}^{2}\right)$. If this abiotic $\mathrm{CO}_{2}$ is evenly distributed over a $2-\mathrm{m}$ vadose zone, the deepest water level observed locally, this will increase soil gas $\mathrm{pCO}_{2}$ by:

$$
\mathrm{pCO}_{2}=\mathrm{nRT} / \mathrm{V}
$$

where $\mathrm{n}=0.23 \mathrm{~mol}, \mathrm{R}$ is gas constant, and $\mathrm{T}$ is the soil temperature $\left(20^{\circ} \mathrm{C}\right.$, or $\left.293.15 \mathrm{~K}\right)$. $\mathrm{V}$ is the volume of soil gas in this $1 \mathrm{~m}$ by $1 \mathrm{~m}$ by $2 \mathrm{~m}$ deep soil profile, and we assume $30 \%$ of porosity ${ }^{12}$ and half of the pore space is occupied by water:

$$
\begin{aligned}
& \mathrm{V}=2 \mathrm{~m}^{3} * 30 \% * 50 \%=0.3 \mathrm{~m}^{3} \\
& \mathrm{pCO}_{2}=0.23 *\left(8.20578 * 10^{-5}\right) * 293.15 / 0.3=18 * 10^{-3} \text { atm or } 1.8 \%
\end{aligned}
$$

These concentrations might vary with porosity, temperature, and other variables, but they are in the same order of magnitude of bulk $\mathrm{pCO}_{2}$ measured in soil gases, providing another line of evidence that abiotic $\mathrm{CO}_{2}$ contribution is detectable through both $\mathrm{CO}_{2}$ concentrations and carbon isotope ratios. If such abiotic $\mathrm{CO}_{2}$ is released to the atmosphere over three weeks until the next irrigation event, the average $\mathrm{CO}_{2}$ efflux can be estimated:

$$
\mathrm{F}_{\mathrm{CO} 2}=\mathrm{n} / \mathrm{t} / \mathrm{S}=0.23 \text { mole } / 3 \text { weeks } / 1 \mathrm{~m}^{2}=0.13 \mu \mathrm{mol} \mathrm{C} \mathrm{m}{ }^{-2} \mathrm{~s}^{-1} \text { or } 48 \mathrm{gC} \mathrm{m}^{-2} \mathrm{yr}^{-1}
$$

However, this efflux is not constant, and its temporal fluctuation is controlled by $\mathrm{CO}_{2}$ production and equally importantly, by gas transport. For example, the irrigation water floods the field and soil gas will be pushed out by water, emitting a large $\mathrm{CO}_{2}$ flux.

Separating naturally formed versus anthropogenic-driven pedogenic carbonates. Sr isotope systematics to trace Ca sources. Sr isotope data were collected on five soil profiles (two on the alfalfa site, two on the pecan site, and one on natural Fabens site) on water leachable (evaporite salts) and acid leachable (mainly pedogenic carbonate) fractions (Appendix Table 3). Soils at the natural Fabens site have a narrow range of ${ }^{87} \mathrm{Sr} /{ }^{86} \mathrm{Sr}$ ratios in the evaporate salts and pedogenic carbonate fractions, between 0.70921 and 0.70941 , and are also similar to dusts in their salt fractions (Fig. 4). However, the pedogenic carbonate of dusts had different $\mathrm{Sr}$ isotopes from their salt fractions. Regional studies have showed that dust is the major contributor of watersoluble Ca onto soil profiles, regulating the accumulation of secondary calcite in natural environments ${ }^{14,45}$.

The salt fraction of the highly managed pecan soils has a larger range of ${ }^{87} \mathrm{Sr} /{ }^{86} \mathrm{Sr}$ ratios $(0.70922-0.71039$ for Pecan_Fine $(\mathrm{n}=29)$; 0.70900-0.71022 for Pecan_Coarse $(\mathrm{n}=20))$ than the pedogenic carbonate fraction (0.70965-0.71002 for Pecan_Fine $(n=28)$; 0.70979-0.71020 for Pecan_Coarse $(n=13))$ (Fig. 4). The less managed alfalfa soils (Alfalfa_Fine_D) have ${ }^{87} \mathrm{Sr} /{ }^{86} \mathrm{Sr}$ ratios of $0.71013-0.71033(\mathrm{n}=7)$ for salt fraction and $0.71005-0.71012$ $(\mathrm{n}=7)$ for pedogenic carbonate (Fig. 4). Both the Rio Grande river water (IRW_RG) and local groundwaters (IRW_GW) are used for irrigation at the pecan orchard but only Rio Grande water was used at the alfalfa site. Their ${ }^{87} \mathrm{Sr} /{ }^{86} \mathrm{Sr}$ ratios are similar $(0.7099$ to 0.7105 , and 0.7096 to 0.7100 , respectively; Appendix Table 2$)$, and fall within the typical range of Sr isotope ratios in Rio Grande measured at other locations near El Paso during different seasons $(0.7089 \text { to } 0.7150)^{33}$. The similarity of Sr isotope ratios between pecan and alfalfa soils to irrigation waters and their difference to the natural site strongly suggest that irrigation dominates Ca inputs onto agricultural soils. This is also in agreement with mass balance of soluble Ca from a previous study at the same site ${ }^{12,14}$ : the irrigation water adds $\sim 130 \mathrm{~g} \mathrm{Ca}^{2+} \mathrm{m}^{-2} \mathrm{yr}^{-1}$, much higher than the fertilizers and other amendments $\left(\sim 30 \mathrm{~g} \mathrm{~m}^{-2} \mathrm{yr}^{-1}\right)$ or atmospheric deposition in the form of rain and dust $\left(\sim 0.1 \mathrm{~g} \mathrm{~m}^{-2} \mathrm{yr}^{-1}\right)$.

The salt fraction of shallow soils at the Pecan_Coarse and Pecan_Fine sites has slightly different Sr isotope ratios from that of deep soils or alfalfa soils or even their pedogenic carbonate fraction, probably due to Ca contribution from fertilizers and soil amendments (e.g., gypsum to lower soil sodicity) or groundwaters. Indeed, groundwater used for irrigation has slightly lower ${ }^{87} \mathrm{Sr} /{ }^{86} \mathrm{Sr}$ ratios than the Rio Grande river and is only applied at the pecan orchard. More likely the application of soil amendments and fertilizers has loaded soluble Ca-bearing salts at the ground surface of the pecan orchard and driven the Sr isotopes to lower values.

$C$ isotope ratios of natural versus anthropogenic pedogenic carbonates. The bulk carbonate in soils is either formed naturally or induced by soil cultivation, and these two endmembers can be differentiated using carbon isotope ratios. Carbon in natural pedogenic carbonates could be sourced from atmospheric $\mathrm{CO}_{2}$, soil respired $\mathrm{CO}_{2}$ and primary carbonate bedrock ${ }^{2,46-49}$. Typically, soil $\mathrm{CO}_{2}$ is a large carbon reservoir and precipitation of secondary calcite is gradual, making soils an open system where pedogenic carbonate formation occurs at isotopic equilibrium with soil-respired $\mathrm{CO}_{2}$. Such relationships have been commonly documented with modern vegetation, soil $\mathrm{CO}_{2}$ and pedogenic calcite in arid to sub-humid environments ${ }^{2,48-50}$.

We modeled the $\delta^{13} \mathrm{C}_{\mathrm{CaCO} 3}$ of natural pedogenic carbonates at equilibrium with soil $\mathrm{CO}_{2}$ derived from $\mathrm{C} 3$ and C4-type vegetation, respectively. The $\delta^{13} \mathrm{C}_{\mathrm{SOC}}$ of $-27 \%$ was used for a typical C3 vegetation (range of -30 to $-24 \%$ ), and $-12 \%$ o for a typical C4 vegetation (range of -16 to $-10 \%$ ) $)^{42,46,47,51-57}$. The soil respired $\mathrm{CO}_{2}$ is typically not fractionated relative to its organic matter sources, but soil $\mathrm{CO}_{2}$ could be enriched in ${ }^{13} \mathrm{C}$ by a maximum of $4.4 \%$, due to fractionation via $\mathrm{CO}_{2}$ diffusion and mixing with atmosphere ${ }^{39,41,58}$. For this exercise, $4.4 \%$ o was assumed. The equilibrium fractionation factors between soil gas $\mathrm{CO}_{2}$, dissolved inorganic carbon species, and calcite were calculated at $20^{\circ} \mathrm{C}^{44}$, the mean annual air temperature for the region. Based on these calculations, naturally formed pedogenic carbonates with $\mathrm{C} 3$ and $\mathrm{C} 4$ types of vegetation would have $\delta^{13} \mathrm{C}_{\mathrm{CaCO} 3}$ values around $-11.5 \%$ and $3.5 \%$, respectively (Fig. $5 \mathrm{~B}$ ). If pedogenic carbonate precipitates at equilibrium with atmospheric $\mathrm{CO}_{2}\left(\delta^{13} \mathrm{C}_{\mathrm{CO} 2}\right.$ at $\left.-8.9 \%{ }^{43}\right)$, the $\delta^{13} \mathrm{C}_{\mathrm{CaCO} 3}$ values would be $\sim 2.2 \%$ (Fig. $5 \mathrm{~B}$ ), overlapping with $\mathrm{C} 4$ vegetation. 
Alternatively, carbon isotope ratios of pedogenic carbonate in irrigated soils may be controlled by $\delta^{13} \mathrm{C}_{\mathrm{DIC}}$ of irrigation water, as shown in Reaction (1) in addition to soil respired $\mathrm{CO}_{2}$ derived from pecan trees (Fig. 1). According to the Rayleigh fractionation model in Fig. 2, irrigation DIC-induced carbonate has distinct $\delta^{13} \mathrm{C}_{\mathrm{CaCO}}$ $(-1.75 \%)^{44}$. The pedogenic carbonate precipitated through DIC from pecan-derived and soil respired $\mathrm{CO}_{2}$ will be at equilibrium with $\delta^{13} \mathrm{C}_{\mathrm{CO} 2}$ (Fig. 1), and its $\delta^{13} \mathrm{C}_{\mathrm{CaCO} 3}$ would be $\sim-9 \%$ on average (Fig. $5 \mathrm{~B}$ ). This is plotted close to the isotope composition of pedogenic carbonate formed naturally in equilibrium with $\mathrm{C} 3$ vegetation derived $\mathrm{CO}_{2}$ since pecan is $\mathrm{C}-3$ vegetation.

Soil inorganic carbon (SIC) contents are higher at the Pecan_Fine site (0.24-1.24 wt\%) than those at Pecan_ Coarse site (0.07-0.66 wt\%) and for each soil profile, SIC peaks around the soil depth of $120 \mathrm{~cm}$, above the finest soil texture (Fig. 5A). Soils at the Pecan_Fine site are finer than those at the Pecan_Coarse site, leading to lower permeability, more ponded water, higher evaporation, less leaching and more salt buildup including secondary calcite ${ }^{14}$. With irrigation and growth of cotton plants or pecan trees, soil gas $\mathrm{pCO}_{2}$ and soil water DIC in modern soils are much higher than those in natural and pre-cultivation soils, and thus carbon in pedogenic carbonates of bulk soils is dominated by anthropogenic sources (Fig. 5B). The carbon isotope compositions of bulk pedogenic carbonates from the two pecan profiles are similar ranging from -3.7 to $-6.0 \%$ and fall in the mixing zone of these two endmembers.

Improve our capacity to quantify and model future changes in pedogenic carbonate accumulation rates and abiotic $\mathrm{CO}_{2}$ emission fluxes. The uncertainty on the relative contribution of old and natural versus irrigation-derived young pedogenic carbonates, or relative contribution of soil respired, atmospheric and abiotic $\mathrm{CO}_{2}\left(\mathrm{X}_{\mathrm{A}}\right.$ or $\mathrm{X}_{\mathrm{B}}$ in Eq. (8)) relies on several assumptions. First, this calculation assumes a uniform $\mathrm{C}$ or $\mathrm{Sr}$ isotope composition for each endmember. For irrigation, this depends on proportion of different water sources and the variation of their $\mathrm{C}$ or $\mathrm{Sr}$ isotope ratios. Regional groundwater typically has much longer age and mixing time with relative constant ${ }^{13} \mathrm{C}_{\mathrm{DIC}}$ or ${ }^{87} \mathrm{Sr} /{ }^{86} \mathrm{Sr}$; however, Rio Grande, the river water has seasonal fluctuation as observed by just several $\mathrm{C}$ and $\mathrm{Sr}$ isotope data reported in this study (Appendix Table 2). Future work is needed to capture all irrigation events for at least one year. It is noted that for the pecan site, farmers switched to pecan production after 60 years of cotton. This transition would have led to a very small shift in the $\mathrm{C}$ isotopes of soil respired $\mathrm{CO}_{2}$, as both cotton and pecan are $\mathrm{C} 3$ crops and have similar carbon assimilation pathways ${ }^{59,60}$.

Second, Eq. (8) assumes two-endmember mixing only, natural and anthropogenic sources. Both soil profiles at the pecan orchard showed less radiogenic Sr isotope values near the ground surface, for both fractions of salts and pedogenic carbonates, but soils at the alfalfa site had nearly constant Sr isotope ratios with depth (Fig. 4). Such a difference might be due to application of soil amendments and fertilizers at the pecan orchard but not at the alfalfa field ${ }^{14}$. Amendments-derived Ca flux is small but could concentrate near surface and shift soil Sr isotopes, especially in the winter months when the soils were collected and before the irrigation dissolved and leached these soluble salts to deeper soils. Only one of the soil treatments reported ${ }^{14}$, urea, was measured for the ${ }^{87} \mathrm{Sr} /{ }^{86} \mathrm{Sr}$ ratio and it was higher than all soil leachates (0.7106). Future Sr isotope measurements on other fertilizers and amendments will better constrain the isotope shift at shallow soils and quantify the Ca inputs.

The accumulation rates of salts and pedogenic carbonate are expected to increase over time in irrigated fields of the Rio Grande valley, threatening agricultural sustainability and increasing its carbon footprint. Soil texture varies with depth and location due to different types of floodplain sediments that deposited several thousands of years ago ${ }^{13}$ and reduced infiltration near the fine-texture soils allows faster salt accumulation rates ${ }^{14}$. As a consequence, the accumulation of secondary salts and carbonate has clogged pores, leading to less leaching and more salt buildup. Such a positive feedback thus projects faster pedogenic carbonate precipitation and more abiotic $\mathrm{CO}_{2}$ emission in the future. This accumulation of pedogenic carbonate can only be reversed if land management practice changes and irrigation with much fresher water leads to dissolution of existing carbonate.

From the perspective of the irrigation water chemistry, the total dissolved solids (TDS) of the groundwater from the alluvial aquifers or the Hueco Bolson and Mesilla Bolson are variable between those of freshwater and brackish water, but typically higher than that of the Rio Grande river ${ }^{14,61,62}$. If the Rio Grande river is less available due to reduced snowfall in Colorado, the headwater region ${ }^{63,64}$, then more groundwater is used for irrigation, accelerating salt loading and pedogenic carbonate formation rates. The salt loading rates through irrigation are proportional to amount of water applied and their chemistry. Flood irrigation is widely used along the Rio Grande valley and other regions where fields inundate with water without any infrastructure ${ }^{65,66}$. The evaporative water loss during the irrigation season is problematic for freshwater-limited drylands. In order to slow down the salt buildup process, much more effective irrigation methods should be used to require less water and load less salt.

Is pedogenic $\mathrm{CO}_{2}$ efflux important to global C cycling? Pedogenic carbonate prevails in dryland systems from subhumid to subarid climate conditions ${ }^{2,67,68}$, and is estimated to contain 700 to $940 \mathrm{Pg}$ of carbon $\left(1 \mathrm{Pg}=10^{15} \mathrm{~g}\right)$, which is similar in size to the atmospheric carbon pool and about two-thirds of soil organic carbon pools ${ }^{2,69-71}$. However, pedogenic carbonate formation in natural drylands is slow, limited by soluble Ca inputs and with almost undetectable abiotic $\mathrm{CO}_{2}$ in field studies ${ }^{72}$.

Our data indicate that continuous supply of $\mathrm{Ca}$ - and DIC-rich irrigation waters has accelerated pedogenic carbonate formation and promoted the subsequent release of abiotic $\mathrm{CO}_{2}$ in dryland agricultural fields. It is critical to assess if this abiotic $\mathrm{CO}_{2}$ is a major component in the carbon cycling. One modeling effort suggested $\sim 2.2$ $\operatorname{Tg~C~} \mathrm{yr}^{-1}\left(1 \mathrm{Tg}=10^{12} \mathrm{~g}\right)$ were emitted to the atmosphere from $\sim 16$ million ha (or 0.16 million $\left.\mathrm{km}^{2}\right)$ of irrigated fields in the western U.S. ${ }^{73}$. This is equivalent to an emission of abiotic $\mathrm{CO}_{2}$ to the atmosphere and accumulation of pedogenic carbonate both at $14 \mathrm{~g} \mathrm{C} \mathrm{m}^{-2} \mathrm{yr}^{-1}$, one to two orders of magnitude higher than these fluxes in natural settings ${ }^{53,74}$. Pedogenic carbonate accumulation rates were quantified at $\sim 1 \mathrm{gC} \mathrm{m}^{-2} \mathrm{yr}^{-1}$ (or $\left.9 \mathrm{gCaCO}_{3} \mathrm{~m}^{-2} \mathrm{yr}^{-1}\right)$ in 
the alfalfa site, but these have been underestimated due to large error bars in U-disequilibrium dating methods ${ }^{13}$. We estimated abiotic $\mathrm{CO}_{2}$ emission at $48 \mathrm{gC} \mathrm{m}^{-2} \mathrm{yr}^{-1}$ through irrigation and if this is true for all other agricultural drylands, then a potential total of $c a .48 \mathrm{gC} \mathrm{m}^{-2} \mathrm{yr}^{-1 *} 0.4$ million $\mathrm{km}^{2}=19 \mathrm{Tg} \mathrm{C} \mathrm{yr}^{-1}$ is released as abiotic $\mathrm{CO}_{2}$ following irrigation. This value is 9 times the flux estimated for southwestern US alone ${ }^{73}$.

Soil salinization has challenged food production, affecting approximately $20 \%$ of irrigated lands globally 5 . Since calcite has lower solubility than evaporite salts, soils with elevated salinity should also be characterized by accumulation of pedogenic carbonates. Combined, these findings suggest dryland agriculture has the potential to significantly alter land-atmosphere $\mathrm{CO}_{2}$ flux over a large area of the Earth's surface.

Two important factors along the Rio Grande valley are soil texture that controls infiltration rates and salt leaching versus accumulation (Pecan_Fine vs. Pecan_Coarse; Alfalfa_Fine vs. Alfalfa_Coarse), and irrigation chemistry and intensity, that dictate the maximum possible loading of salts (river water vs. groundwater) ${ }^{12,14}$. These are similar to the chemistry of irrigation water and hydrological conditions emphasized in previous models $s^{73}$, and so, abiotic $\mathrm{CO}_{2}$ efflux rates associated with pedogenic carbonate accumulation are likely to vary significantly among agricultural settings.

\section{Conclusion}

To summarize, both irrigation waters and fertilizers/soil amendments load DIC and $\mathrm{Ca}^{2+}$ and promote the accumulation of pedogenic carbonate. This has not only increased SIC contents, but also shifted carbon and strontium isotope ratios of pedogenic carbonate in the agricultural fields. Accumulation rates of pedogenic carbonates are greatly elevated due to flood irrigation even if soil cultivation with flood irrigation has only occurred for the last 100 years, and even in soils that have naturally accumulated secondary calcite over thousands of years since the deposits of these flood plains of the Rio Grande.

Evaporite salts and pedogenic carbonates in agricultural soils have ${ }^{87} \mathrm{Sr} /{ }^{86} \mathrm{Sr}$ signatures similar to irrigation waters (Rio Grande and local groundwater), with slight modification from soil amendments and fertilizers near the soil surface. In contrast, different ${ }^{87} \mathrm{Sr} /{ }^{86} \mathrm{Sr}$ ratios in salt vs. pedogenic carbonates are observed in natural soils, indicative of dust-derived Ca. Similarly, carbon isotopes of pedogenic carbonate in these soils fall within the range of two endmembers, soil respired $\mathrm{CO}_{2}$ from $\mathrm{C} 3$ crop and DIC in the irrigation water. This study has clearly identified that the pedogenic carbonates in agricultural soils along the Rio Grande valley are predominantly formed by loading of dissolved inorganic carbon and dissolved calcium through flood-irrigation. This is in agreement with a mass balance calculation at the same sites that showed irrigation loaded approximately $350 \mathrm{~g} \mathrm{Ca}^{2+} \mathrm{m}^{-2} \mathrm{yr}^{-1}$, much higher than natural sources as rain or dust $\mathrm{t}^{14}$.

Because of the coupling between calcite production and $\mathrm{CO}_{2}$ release in Reaction (1), we conclude that calcitederived $\mathrm{CO}_{2}$ is an important $\mathrm{CO}_{2}$ source in agricultural soils. Indeed, Keeling plots of soil gas samples in a pecan orchard revealed the contribution of such an abiotic $\mathrm{CO}_{2}$ endmember. To the best of our knowledge, irrigation derived $\mathrm{CO}_{2}$ is observed for the first time in our field studies. This adds to the literature that mineral-water interaction has the potential to modify $\mathrm{CO}_{2}$ efflux and our estimates of soil respired rates.

Based on this study and previous works, soil texture, irrigation intensity, and water chemistry are identified as the dominant controls on accumulation rates of pedogenic carbonate and emission fluxes of abiotic $\mathrm{CO}_{2}$. If land management practices are not changed to decrease salt loading by irrigation, negative consequences are expected, where secondary minerals will clog pores and reduce infiltration, leading to elevated sodicity and salinity and accelerating calcite precipitation rates and subsequent $\mathrm{CO}_{2}$ emissions. Future climate projections will likely amplify pressures in this region: reduced river flow in the future may promote use of more concentrated groundwater, and hot/dry summers may lead to more evaporative water loss. Additional studies are needed to identify major variables that control the pedogenic carbonate accumulation rates and the accompanied abiotic $\mathrm{CO}_{2}$ emission, to investigate the temporal and spatial variability within an agricultural field, and more importantly scale up from the Rio Grande valley to other dryland regions.

Received: 28 May 2021; Accepted: 17 December 2021

Published online: 10 January 2022

\section{References}

1. Reynolds, J. F. et al. Global desertification: Building a science for dryland development. Science 316(5826), 847-851 (2007).

2. Zamanian, K., Pustovoytov, K. \& Kuzyakov, Y. Pedogenic carbonates: Forms and formation processes. Earth Sci. Rev. 157, 1-17 (2016).

3. Ghassemi, F., Jakeman, A. J. \& Nix, H. A. Salinisation of Land and Water Resources: Human Causes, Extent, Management and Case Studies 526 (CABI Publishing, 1995).

4. Mashali, A. M. Integrated soil management for sustainable use of salt-affected soils and network activities. In Proceedings of the International Workshop on Integrated Soil Management for Sustainable Use of Salt-Affected Soils, 55-75 (Bureau of Soils and Water Management, 1995).

5. Shahid, S. A., Zaman, M. \& Heng, L. Soil salinity: Historical perspectives and a world overview of the problem. In Guideline for Salinity Assessment, Mitigation and Adaptation Using Nuclear and Related Techniques (Springer, 2018). https://doi.org/10.1007/ 978-3-319-96190-3_2.

6. Miyamoto, S. \& Storey, J. B. Soil management in irrigated pecan orchards in the southwestern United States. HortTechnology 5, 219-222 (1995).

7. Arguez, A. et al. NOAA's 1981-2010 U.S. climate normals: An overview. Bull. Am. Meterol. Soc. https://doi.org/10.1175/BAMSD-11-00197.1 (2012).

8. Ganjegunte, G. K., Clark, J. A., Parajulee, M. N., Enciso, J. \& Kumar, S. Salinity management in Pima cotton fields using sulfur burner. Agrosyst. Geosci. Environ. 1, 1-10 (2018).

9. Ganjegunte, G. K., Sheng, Z. \& Clark, J. Soil salinity and sodicity appraisal by electromagnetic induction in soils irrigated to grow cotton. Land Degrad. Dev. https://doi.org/10.1002/ldr.1162 (2012). 
10. Sheng, Z. \& Liu, Y. Evapotranspiration of flood-irrigated pecans under drought conditions in El Paso, TX. In Emerging Technologies for Sustainable Irrigation, A Joint ASABE/IA Irrigation Symposium (2015).

11. Sheng, Z. Impacts of groundwater pumping and climate variability on groundwater availability in the Rio Grande Basin. Ecosphere 4(1), 5. https://doi.org/10.1890/ES12-00270.1 (2013).

12. Cox, C. et al. Changes of soil quality due to flood irrigation in agricultural fields along the Rio Grande in western Texas. Appl. Geochem. 90, 87-100. https://doi.org/10.1016/j.apgeochem.2017.12.019 (2018).

13. Doser, D. et al. Using geophysics to investigate texture and salinity of agricultural soils and their impact on crop growth in El Paso County, Texas. J. Environ. Eng. Geophys. 24, 465-477. https://doi.org/10.2113/JEEG24.3.465 (2019).

14. Ortiz, A. C. \& Jin, L. Chemical and hydrological controls on salt accumulation in irrigated soils of southwestern U.S. Geoderma https://doi.org/10.1016/j.geoderma.2021.114976 (2021).

15. Szynkiewicz, A., Witcher, J. C., Modelska, M., Borrok, D. M. \& Pratt, L. M. Anthropogenic sulfate loads in the Rio Grande, New Mexico (USA). Chem. Geol. 283(3-4), 194-209. https://doi.org/10.1016/j.chemgeo.2011.01.017 (2011).

16. Borrok, D. M. \& Engle, M. A. The role of climate in increasing salt loads in dryland rivers. J. Arid Environ. 111, 7-13 (2014).

17. Amundson, R. G. \& Lund, L. J. The stable isotope chemistry of a native and irrigated Typic Natrargid in the San-Joaquin Valley of California. Soil Sci. Soc. Am. J. 51(3), 761-767 (1987).

18. Lal, R. Soil carbon sequestration to mitigate climate change. Geoderma 123(1-2), 1-22 (2004).

19. Kaye, J. P. et al. Hierarchical Bayesian scaling of soil properties across urban, agricultural, and desert ecosystems. Ecol. Appl. 18(1), $132-145$ (2008).

20. Entry, J. A., Sojka, R. E. \& Shewmaker, G. E. Irrigation increases inorganic carbon in agricultural soils. Environ. Manag. 33(S1), S309-S317. https://doi.org/10.1007/s00267-003-9140-3 (2004).

21. Wohlfahrt, G., Fenstermaker, L. F. \& Arnone, J. A. Large annual net ecosystem $\mathrm{CO}_{2}$ uptake of a Mojave Desert ecosystem. Glob. Change Biol. 14, 1475-1487 (2008).

22. Xie, J., Li, Y., Zhai, C., Li, C. \& Lan, Z. $\mathrm{CO}_{2}$ absorption by alkaline soils and its implication to the global carbon cycle. Environ. Geol. 56, 953-961 (2009).

23. Wang, X. et al. Carbon accumulation in arid croplands in northwest China: Pedogenic carbonate exceeding organic carbon. Sci. Rep. 5, 11439. https://doi.org/10.1038/srep11439 (2015).

24. Bughio, M. A. et al. Neoformation of pedogenic carbonates by irrigation and fertilization and their contribution to carbon sequestration in soil. Geoderma 262, 12-19 (2016).

25. Schlesinger, W. H. Carbon sequestration in soils: Some cautions amidst optimism. Agric. Ecosyst. Environ. 82, 121-127 (2000).

26. Serna-Perez, A., Monger, H. C., Herrick, J. E. \& Murray, L. Carbon dioxide emissions from exhumed petrocalcic horizons. Soil Sci. Soc. Am. J. 70, 795-805 (2006).

27. Sanderman, J. Can management induced changes in the carbonate system drive soil carbon sequestration? A review with particular focus on Australia. Agric. Ecosyst. Environ. 155, 70-77 (2012).

28. Chevallier, T., Cournac, L., Hamdi, S., Gallali, T. \& Bernoux, M. Temperature dependence of $\mathrm{CO}_{2}$ emissions rates and isotopic signature from a calcareous soil. J. Arid Environ. 135, 132-139. https://doi.org/10.1016/j.jaridenv.2016.08.002 (2016).

29. Schlesinger, W. H. An evaluation of abiotic carbon sinks in deserts. Glob. Change Biol. 23, 25-27 (2017).

30. Gallagher, T. M. \& Breecker, D. O. The obscuring effects of calcite dissolution and formation on quantifying soil respiration. Glob. Biogeochem. Cycles 34, e2020GB006584. https://doi.org/10.1029/2020GB006584 (2020).

31. Hawley, J. W. \& Lozinsky, R. P. Hydrogeologic framework of the Mesilla Basin in New Mexico and western Texas: New Mexico Bureau of mines and mineral resources. Open File Rep. 323, 55 (1992).

32. Miyamoto, S. Soil Resources of El Paso: Characteristics, Distribution and Management Guidelines (Texas Agricultural Experiment Station Bulletin, 2000).

33. Nyachoti, S. K., Jin, L., Tweedie, C. E. \& Ma, L. Formation of pedogenic carbonates in the semi-arid Rio Grande valley: Insights from carbon, major elements, and $\mathrm{U}$-series isotopes in natural and agricultural soils of southern New Mexico and western Texas. Chem. Geol. https://doi.org/10.1016/j.chemgeo.2017.10.014 (2018).

34. Ganor, E. Atmospheric dust in Israel. In Sedimentological and Meteorological Analysis of Dust Deposition (Ph.D. thesis) (Hebrew University of Jerusalem, 1975).

35. Reheis, M. C. Dust deposition and its effect on soils-A progress report. In Desert Winds: Monitoring Wind-Related Surface Processes in Arizona, New Mexico, and California (eds. Breed, C. S., \& Reheis, M. C.), 123-131 (U.S. Geological Survey Professional Paper 1598, 1999).

36. Shannak, B., Corsmeier, U., Kottmeier, Ch. \& Al-azab, T. Wind tunnel study of twelve dust samples by large particle size. Atmos. Environ. 98, 442-453 (2014).

37. Konter, J. G. \& Storm, L. P. High precision ${ }^{87} \mathrm{Sr} /{ }^{86} \mathrm{Sr}$ measurements by MC-ICP-MS, simultaneously solving for $\mathrm{Kr}$ interferences and mass-based fractionation. Chem. Geol. 385, 26-34 (2014).

38. Jweda, J., Bolge, L., Class, C. \& Goldstein, S. L. High presicion Sr-Nd-Hf-Pb isotopic composition of USGS reference material BCR-2. Geostand. Geoanal. Res. https://doi.org/10.1111/j.1751-908X.2015.00342.x (2015).

39. Jin, L. et al. The $\mathrm{CO}_{2}$ consumption potential during gray shale weathering: Insights from the evolution of carbon isotopes in the Susquehanna Shale Hills critical zone observatory. Geochim. Cosmochim. Acta 142, 260-280 (2014).

40. Hasenmueller, E. A. et al. Topographic controls on the depth distribution of soil $\mathrm{CO}_{2}$ in a small temperate watershed. Appl. Geochem. 63, 58-69 (2015).

41. Jin, L. et al. Inorganic carbon isotope systematics in soil profiles undergoing silicate and carbonate weathering (Southern Michigan, USA). Chem. Geol. 264, 139-153 (2009).

42. Trumbore, S. E., Chadwick, O. A. \& Amundson, R. Rapid exchange between soil carbon and atmospheric carbon dioxide driven by temperature change. Science 272(5260), 393-396 (1996).

43. Frank, A. H. et al. Geological $\mathrm{CO}_{2}$ quantified by high-temporal resolution stable isotope monitoring in a salt mine. Sci. Rep. 10(1), $1-9(2020)$.

44. Clark, I. \& Fritz, P. Environmental Isotopes in Hydrogeology (CRC Press, 1997).

45. Capo, R. C. \& Chadwick, O. A. Sources of strontium and calcium in desert soil and calcrete. Earth Planet. Sci. Lett. 170, 61-72 (1999).

46. Ehleringer, J. R., Sage, R. F., Flanagan, L. B. \& Pearcy, R. W. Climate change and the evolution of C4 photosynthesis. Trends Ecol. Evol. 6, 95-99 (1991).

47. Vogel, J. C. Variability of carbon isotope fractionation during photosynthesis. In Stable Isotopes and Plant Carbon-Water Relations (eds Ehleringer, J. R. et al.) 29-38 (Academic Press, 1993).

48. Quade, J., Chivas, A. R. \& McCulloch, M. T. Stronsium and carbon isotope tracers and the origins of soil carbonate in southern Australia and Victoria. Palaeogeogr. Palaeloclimatol. Palaeloecol. 113, 103-117 (1995).

49. Breecker, D. O., Sharp, Z. D. \& McFadden, L. D. Seasonal bias in the formation and stable isotopic composition of pedogenic carbonate in modern soils from central New Mexico, USA. Geol. Soc. Am. Bull. 121, 630-640 (2009).

50. Amundson, R. G., Chadwick, O. A., Sowers, J. M. \& Doner, H. E. Relationship between climate and vegetation and the stable carbon isotope chemistry of soils in the eastern Mojave Desert, Nevada. Quat. Res. 29, 245-254 (1988).

51. Cerling, T. E. \& Quade, J. Stable carbon and oxygen isotopes in soil carbonates. In Climate Change in Continental Isotopic Records (eds Swart, P. et al.) 217-231 (American Geophysical Union Geophysical Monograph, 1993). 
52. Rowe, P. J. \& Maher, B. A. 'Cold' stage formation of calcrete nodules in the Chinese Loess Plateau: Evidence from U-series dating and stable isotope analysis. Palaeogeogr. Palaeloclimatol. Palaeloecol. 157, 109-125 (2000).

53. Landi, A., Mermut, A. R. \& Anderson, D. W. Origin and rate of pedogenic carbonate accumulation in Saskatchewan soils, Canada. Geoderma 117, 143-156 (2003).

54. Retallack, G. J. Pedogenic carbonate proxies for amount and seasonality of precipitation in paleosols. Geology 33, 333-336 (2005).

55. Sheldon, N. D. \& Tabor, N. J. Quantitative paleoenvironmental and paleoclimatic reconstruction using paleosols. Earth Sci. Rev. 95, 1-52 (2009).

56. Kraimer, R. A. \& Monger, H. C. Carbon isotopic subsets of soil carbonate-A particle size comparison of limestone and igneous parent materials. Geoderma 150, 1-9 (2009).

57. Montanez, I. P. Modern soil system constraints on reconstructing deep-time atmospheric $\mathrm{CO}_{2}$. Geochim. Cosmochim. Acta 101, 57-75 (2013).

58. Quade, J., Cerling, T. E. \& Bowman, J. R. Systematic variations in the carbon and oxygen isotopic composition of pedogenic carbonate along elevation transects in the southern Great Basin, United States. Geol. Soc. Am. Bull. 101, 375-464 (1989).

59. Prasifka, J. \& Heinz, K. The use of C3 and C4 plants to study natural enemy movement and ecology, and its application to pest management. Int. J. Pest Manag. https://doi.org/10.1080/09670870410001731907 (2010).

60. Saranga, Y., Flash, I., Paterson, A. H. \& Yakir, D. Carbon isotope ratio in cotton varies with growth stage and plant organ. Plant Sci. 142(1), 47-56 (1999).

61. Sheng, Z. Impacts of groundwater pumping and climate variability on groundwater availability in the Rio Grande Basin. Ecosphere 4(1), Art5. https://doi.org/10.1890/ES12-00270.1 (2013).

62. Dettinger, M., Udall, B. \& Georgakakos, A. Western water and climate change. Ecol. Appl. 25(8), 2069-2093 (2015).

63. Elias, E., Reyes, J., Steele, C. \& Rango, A. Diverse landscapes, diverse risks: Synthesis of the special issue on climate change and adaptive capacity in a hotter, drier Southwestern United States. Clim. Change 2018(148), 339-353. https://doi.org/10.1007/s10584018-2219-x (2018).

64. Williams, A. P. et al. Large contribution from anthropogenic warming to an emerging North American megadrought. Science 368, 314-318 (2020).

65. Liu, Z. et al. Effects of winter irrigation on soil salinity and jujube in arid regions. PLoS ONE 14(6), e0218622. https://doi.org/10. 1371/journal.pone.0218622 (2019).

66. Shrivastava, P. \& Kumar, R. Soil salinity: A serious environmental issue and plant growth promoting bacteria as one of the tools for its alleviation. Saudi J. Biol. Sci. 22, 123-131 (2015).

67. Gocke, M., Pustovoytov, K. \& Kuzyakov, Y. Pedogenic carbonate formation: Recrystallization versus migration-process rates and periods assessed by 14C labeling. Glob. Biogeochem. Cycles 26, GB1018. https://doi.org/10.1029/2010GB003871 (2012).

68. Dahms, D. \& Egli, M. Carbonate and elemental accumulation rates in arid soils of mid-to-late Pleistocene outwash terraces, southeastern Wind River Range, Wyoming, USA. Chem. Geol. 446, 147-162 (2016).

69. Schlesinger, W. H. Carbon storage in the caliche of arid soils: A case study from Arizona. Soil Sci. 133, 247-255 (1982).

70. Eswaran, H. et al. Global carbon stocks. In Global Climate Change and Pedogenic Carbonates (eds Lal, J. M. K. R. \& Stewart, B. A.) 15-26 (CRC/Lewis Press, 2000).

71. Plaza, C. et al. Soil resources and element stocks in drylands to face global issues. Sci. Rep. 8, 13788. https://doi.org/10.1038/ s41598-018-32229-0 (2018).

72. Monger, H. C. \& Gallegos, R. A. Biotic and abiotic processes and rates of pedogenic carbonate accumulation in the southwestern United States-Relationship to atmospheric $\mathrm{CO}_{2}$ sequestration. In Global Climate Change and Pedogenic Carbonates, 273-289 (CRC, 2000).

73. Suarez, D. L. Impact of agriculture on $\mathrm{CO}_{2}$ as affected by changes in inorganic carbon'. In Global Climate Change and Pedogenic Carbonates (eds Lal, R. et al.) 257-272 (CRC/Lewis Publishers, 2000).

74. Eghbal, M. K. \& Southard, R. J. Stratigraphy and genesis of Durorthids and Haplargids on dissected alluvial fans, western Mojave Desert, California. Geoderma 59, 151-174 (1993).

\section{Acknowledgements}

Financial support for this study is from the National Science Foundation under award \# 1853680. N.O. and B.K. also acknowledge support from national programme P1-0143 and project J1-1716 by the Slovenian Research Agency (ARRS). We acknowledge the assistance in the field and laboratory from undergraduate students at The University of Texas at El Paso: Karen Valles, Isaac Martinez, Andrea Lopez, Paola Soto-Moreno, and Francisco Chavez. We also thank the Art Ivey Family, owners of Rio Bravo Farms for allowing us to use their properties in this study.

\section{Author contributions}

L.J. and A.O. designed the work, collected and analyzed the data, and wrote the manuscript. N.O., J.K., and L.M. helped with data collection and improved the manuscript. B.K. contributed to data collection.

\section{Competing interests}

The authors declare no competing interests.

\section{Additional information}

Supplementary Information The online version contains supplementary material available at https://doi.org/ 10.1038/s41598-021-04226-3.

Correspondence and requests for materials should be addressed to L.J.

Reprints and permissions information is available at www.nature.com/reprints.

Publisher's note Springer Nature remains neutral with regard to jurisdictional claims in published maps and institutional affiliations. 
(c) (i) Open Access This article is licensed under a Creative Commons Attribution 4.0 International cc) License, which permits use, sharing, adaptation, distribution and reproduction in any medium or format, as long as you give appropriate credit to the original author(s) and the source, provide a link to the Creative Commons licence, and indicate if changes were made. The images or other third party material in this article are included in the article's Creative Commons licence, unless indicated otherwise in a credit line to the material. If material is not included in the article's Creative Commons licence and your intended use is not permitted by statutory regulation or exceeds the permitted use, you will need to obtain permission directly from the copyright holder. To view a copy of this licence, visit http://creativecommons.org/licenses/by/4.0/.

(C) The Author(s) 2022 